\title{
Analysis of Structures of Oligomeric Siloxanes from Dimethoxydimethylsilane under Heat Treatment by FT-IR
}

\author{
Nozomu TAKANO, ${ }^{\dagger}{ }^{\dagger \dagger}$ Tomio FUKUDA, ${ }^{*}$ and Katsumichi ONO \\ Department of Materials Science, Ibaraki University, 4-12-1 Nakanarusawacho, Hitachi 316-8511, Japan \\ ${ }^{*}$ Research \& Development Center, Hitachi Chemical Co., Ltd., Shimodate 308-8251, Japan
}

(Received November 14, 2000; Accepted March 7, 2001)

\begin{abstract}
The structures of dimethoxydimethylsilane oligomers were investigated before and after heat treatment. FT-IR CIRCLE was used to analyze the structures of siloxane oligomers in solution before annealing, and diffuse reflectance was used to analyze them after annealing. Linear siloxane components were predominant in oligomer solution, while half the volume fraction was changed into ring form after annealing. Ring formation proceeded further with increasing molecular weight of the oligomer in solution. When hydrochloric acid $(\mathrm{HCl})$ was used as catalyst for the reaction, the fraction of linear siloxane component was higher and ring formation was easier than without catalyst or with basic DMF catalyst.

KEY WORDS Siloxane Oligomer / Heat Treatment / Fourier Transform Infrared Spectrometry (FT-
\end{abstract}

IR) / CIRCLE Cell Method/ Diffuse Reflectance Spectroscopy / Alkoxysilane / Linear Siloxane /

Adhesive properties of the interface between inorganic and organic materials (hereafter referred to as "interface") are very important factors for the preparation of composite materials since they conclusively govern characteristic properties in many cases. Studies have been carried out to make clear the relation between the structure of the interface and the physical properties of the composite.

Most generally, silane or other coupling agents are used to enhance the adhesive properties of the surface of inorganic materials. ${ }^{1}$ Coupling processes are usually accompanied by heat treatment. In the processing of polymer composites, heat treatment proceeds in the molding process.

The term "interface" has been used to represent the virtual molecular surfaces between different materials. $\mathrm{H}$. Ishida and C. Ching et al. emphasize the importance of the concept "interphase" which denotes a interfacial region with certain thickness. ${ }^{1-4}$ There exists two different layers in the vicinity of the interface of composite materials, one is the layer in which silane coupling agent is chemically absorbed and the other is the layer in which is physically absorbed. Matrix resin in the vicinity of the interphase is significantly affected by silane coupling agent migrated from the physically absorbed layer. Change in physical properties of the matrix resin has been considered to significantly affect the characteristics of the composite including adhesive properties.

Another important factor controlling the physical properties of the composite is residual strain. Residual strain develops on the interphase sandwiched between materials having substantially different elastic modulus or thermal expansion coefficient. Reduction of elastic modulus of the interphase may be effective in reducing this residual strain. Coupling agents having linear components and long-linear siloxane skeleton were recently proposed as effective means to reduce elastic modulus. ${ }^{5,6}$
It has not been well known, however, what kind of siloxane skeleton exists on the surface of inorganic materials after heat treatment. This seems to be the reason that the quantitative relation between the structure of siloxane skeleton and adhesive properties of the interphase has not been established yet.

Taking into account the above factors, it is important to reduce migration of the coupling agent from the physically absorbed layer and form a low elastic modulus layer for the improvement of the adhesive properties of interphase. Thus it is necessary to develop coupling agents which form relatively thick layers in the vicinity of interphase and generate higher amount of linear siloxane component after heat treatment.

To determine the ideal state of interface for enhanced adhesive properties, we have studied the relation between the conditions of heat treatment and structure of siloxane formed in the vicinity of interface. The chemical structure of siloxane after heat treatment could be easily determined by FT-IR diffuse reflectance using specimens made by directly treating a variety of alkoxysilane with $\mathrm{KBr}$. Increase of the linear siloxane component has been achieved by dimethoxydimethylsilane, lower concentration silane compounds, and low boiling point alcholic solvent. 7

In this study, we used pre-reacted oligomer of dimethoxydimethylsilane to further improve the yield of linear siloxane. The chemical structure after heat treatment was analyzed by FT-IR.

\section{EXPERIMENTAL}

\section{Reagents}

Dimethoxydimethylsilane (hereinafter referred to as "DMDM") from Tokyo Chemical Co., Ltd. was used. Special reagent grade methanol with $99.5 \%$ purity from Wako Chemical was used without further purification

\footnotetext{
${ }^{\dagger}$ On leave from Research \& Development Center, Hitachi Chemical Co., Ltd., Ogawa 1500, Shimodate 308-8251, Japan.

${ }^{\dagger}{ }^{\dagger}$ To whom correspondence should be addressed.
} 
for the solvent for pre-reaction. Hydrochloric acid $(\mathrm{HCl})$ and dimethylformamide (DMF) from Wako Chemicals were used as catalysts.

\section{Pre-Reaction of DMDM}

Pre-reaction of DMDM was carried out by adding catalyst to the DMDM solution adjusted to a desired concentration by methanol, and then agitating the solution for 1 to $4 \mathrm{~h}$ at room temperature. The concentrations of $\mathrm{HCl}$ and DMF were 0 to $40 \mathrm{~mol} \%$ with respect to methoxy group of DMDM. The concentration of DMDM oligomer solution between 0.1 to 20 vol\% was made. Numberaveraged molecular weight $\left(M_{\mathrm{n}}\right)$ of the obtained oligomer of DMDM ("DMDM oligomer") was measured by gel permeation chromatography (GPC) equipped with columns for methanol solvent from Hitachi Chemical Co. (GL-W 530 and GL-W 540). The molecular weight of the oligomer was determined by gel permeation chromatography (GPC) with polyethylene glycol as standard using methanol eluate. The number of siloxane unit of DMDM oligomer was 5 to 8 .

\section{The Method of Oligomer Analysis and Heat Treatment}

Using DMDM oligomer solution obtained from above processes, we investigated the chemical structure of siloxane before and after heat treatment with FT-IR (FTIR FTS-60 from BIO-RAD Inc.). The chemical structure of siloxane in DMDM oligomer solution before heat treatment was analyzed according to the Circle Cell method ("CIRCLE"). ${ }^{6,8}$ CIRCLE is a kind of ATR (Attenuated total reflection), and effective in measuring a solution with high sensitivity. The spectrum of the solution was measured with reference to methyl alcohol as solvent. ZnSe was selected for CIRCLE. Resolution and the number of scans were set at 4 and $32 \mathrm{~cm}^{-1}$, respectively. Since CIRCLE allows determination of the chemical structure of a target molecule in solution as it is, Ikuta et al. estimated the change of silane coupling agent in solution with time. ${ }^{9}$

To simplify experimental estimation of siloxane formation, heat treatment of DMDM oligomer solution was done by treating it on $\mathrm{KBr}$ powder used for IR measurement, as in the previous paper. ${ }^{7} 0.2$ to $0.5 \mathrm{~g}$ of DMDM oligomer solution was directly dripped on 1 to $2 \mathrm{~g}$ of $\mathrm{KBr}$, milled in an agate mortar, and treated at $70^{\circ} \mathrm{C}$ for $5 \mathrm{~min}$. Measurement by FT-IR was carried out within $1 \mathrm{~h}$ after heat treatment. Diffuse reflectance was used as in the previous report for analysis of the chemical structure of siloxane of DMDM oligomer. ${ }^{7}$ Kubelka-Munk correction was carried out for all IR spectra.

Although FT-IR is frequently used for identification and analysis of silane compound, ${ }^{10}$ investigation utilizing CIRCLE or diffused reflectance is relatively few. This study applied these methods to simplify the assignments of linear and ring components of siloxane before and after heat treatment. Quantitative comparison of the spectra obtained from CIRCLE and diffuse reflectance method, however, is rather difficult because of differences in background. Thus we mainly identified and compared the fractional ratios of siloxane components in the solid state by diffuse reflectance spectroscopy unless otherwise indicated as CIRCLE. In the presence of acidic or basic catalyst, alkoxy groups such as methoxy group of silane compound are easily hydrolyzed to give silanol group. After repeated dehydration or dealcoholization condensation, they become polysiloxane. In acidic environment, linear siloxane tends to be generated, while cross-linked siloxane results more frequently in alkaline environment. ${ }^{11}$

IR spectrum of siloxane component has a strong absorption band at 1020 to $1090 \mathrm{~cm}^{-1}$. Linear siloxane exhibits absorption band at 1020 to $1050 \mathrm{~cm}^{-1}$ (stretching vibration of $\mathrm{Si}-\mathrm{O}-\mathrm{Si}$ of linear siloxane). The absorption of four-membered ring siloxane appears at 1050 to 1080 $\mathrm{cm}^{-1}$ (stretching vibration of $\mathrm{Si}-\mathrm{O}-\mathrm{Si}$ of 4-membered linear siloxane) and macro-cyclic siloxane at 1080 to 1090 $\mathrm{cm}^{-1}$ (stretching vibration of $\mathrm{Si}^{-} \mathrm{O}-\mathrm{Si}$ of large ring siloxane). Absorption of methylsilane and dimethysilane is at 1250 to $1260 \mathrm{~cm}^{-1}$ and 800 to $850 \mathrm{~cm}^{-1}$ (stretching vibration of Si-C). ${ }^{12,13}$ In conventional transmission, however, siloxane bands usually appear as a single broad absorption in the vicinity of 1020 to $1050 \mathrm{~cm}^{-1}$. Thus it is impossible to resolve individual components.

For identification of siloxane components in the present study, methoxy group was assigned as the band in the vicinity of $2860 \mathrm{~cm}^{-1}$ (A), linear siloxane in the vicinity of 1020 to $1050 \mathrm{~cm}^{-1}$ (E), macro-cyclic siloxane in the vicinity of 1050 to $1080 \mathrm{~cm}^{-1}(\mathrm{C}), 4$-membered ring siloxane in the vicinity of 1080 to $1095 \mathrm{~cm}^{-1}(\mathrm{D})$, and $\mathrm{CH}_{3}$ $-\left(\mathrm{SiO}_{3}\right)$ and $\left(\mathrm{CH}_{3}\right)_{2}-\left(\mathrm{SiO}^{-}\right)_{2}$ in the vicinity of $1265 \mathrm{~cm}^{-1}$ (B). As shown in our previous paper, ${ }^{7} \mathrm{C}$ and $\mathrm{D}$ can be separated. In this study, however, the resolution of $\mathrm{C}$ and $\mathrm{D}$ was difficult and only the sum of ring components $(\mathrm{C}+\mathrm{D})$ was evaluated. The ratio of linear siloxane, considered to be a measure for reducing the modulus of interfacial region, was evaluated in terms of $\mathrm{E} /(\mathrm{C}+\mathrm{D}+\mathrm{E})$. The ratio of unreacted methoxy group was evaluated by A/B. A broad absorption band in the vicinity of 3300 $\mathrm{cm}^{-1}$ arising from silanol group is affected by adsorbed water, so this was not used for evaluation.

\section{RESULTS AND DISCUSSION}

Structure of DMDM Oligomer before and after Annealing

The oligomer used was obtained by adding $1.0 \mathrm{~mol} \%$ of $\mathrm{HCl}$ to the 5 vol\% methanol solution of DMDM and leaving it to react for $4 \mathrm{~h}$ at room temperature. It was annealed at $70^{\circ} \mathrm{C}$ for $5 \mathrm{~min}$. Figure 1 shows IR spectra of DMDM oligomer before and after annealing. After annealing, the absorption band corresponding to ring siloxane increased to almost the same level as that of linear siloxane. This means that almost all siloxane components in DMDM oligomer solution are linear siloxane components, and considerable amounts of them are changed into ring components after annealing. Figure 2 shows the IR spectrum of dimethoxydimethylsilane after annealing. In contrast with annealed DMDM oligomer, absorption originating from ring siloxane components was hardly observed in annealed dimethoxydimethylsilane.

Next, we examined the effects of the time of the prereaction of DMDM. The number averaged molecular weight, $M_{\mathrm{n}}$, of the oligomer was expected to increase with reaction time. Figure 3 shows the relationship between pre-reaction time and $M_{\mathrm{n}}$ of the DMDM oligomer. Pre-reaction was carried out for 5 vol\% methanolic solu- 


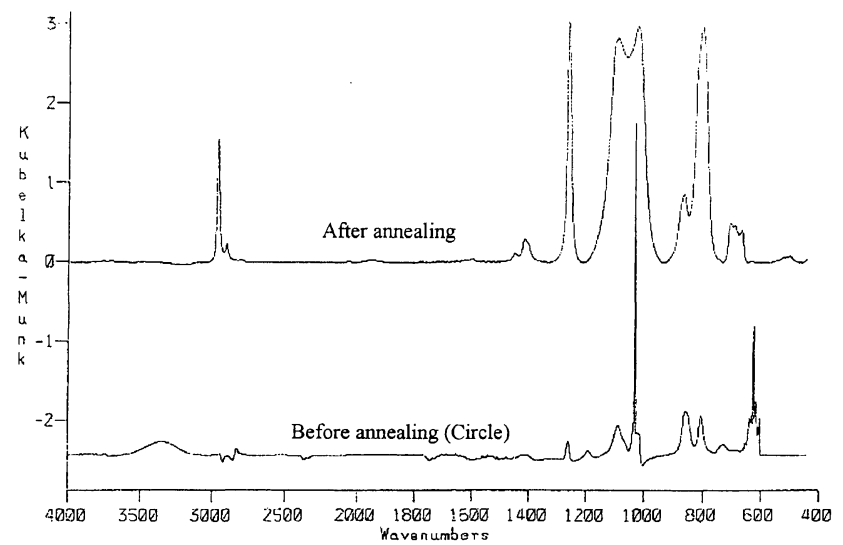

Figure 1. IR spectra of DMDM oligomer before and after annealing. Concentration, $5 \mathrm{vol} \% ; \mathrm{HCl}, 1.0 \mathrm{~mol} \%$ of methoxy group; annealed at $70^{\circ} \mathrm{C}$ for $5 \mathrm{~min}$.

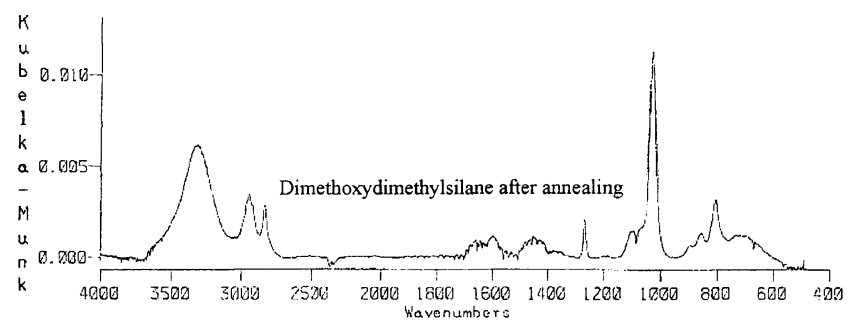

Figure 2. IR spectra of dimethoxydimethylsilane after annealing. Concentration, $5 \mathrm{vol} \% ; \mathrm{HCl}, 1.0 \mathrm{~mol} \%$ of methoxy group; annealed at $70^{\circ} \mathrm{C}$ for $5 \mathrm{~min}$.

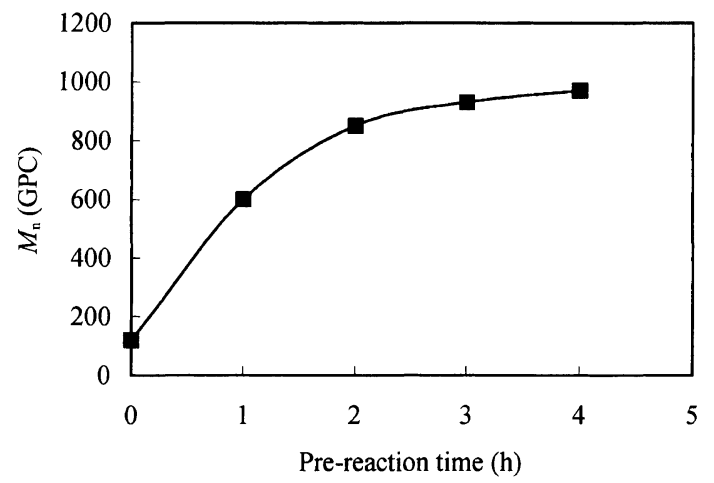

Figure 3. Plots of molecular weight $\left(M_{\mathrm{n}}\right)$ of oligomer against prereaction time. Concentration, $5 \mathrm{vol} \% ; \mathrm{HCl}, 4.0 \mathrm{~mol} \%$ of methoxy group.

tion of DMDM with the addition of $4.0 \mathrm{~mol} \%$ of hydrochloric acid. $M_{\mathrm{n}}$ of DMDM oligomer increased during the first two hours, and then reached almost a constant value of $c a .1000$ corresponding to the repeating unit of 6 . We examined the structure of siloxane of DMDM oligomer solution obtained in this way according to CIRCLE.

The fractional ratios of unreacted methoxy group (A/ $\mathrm{B})$ and linear siloxane component $\mathrm{E} /(\mathrm{C}+\mathrm{D}+\mathrm{E})$ of annealed samples are plotted against $M_{\mathrm{n}}$ in Figure 4. A/B decreased with $M_{\mathrm{n}}$, while $\mathrm{E} /(\mathrm{C}+\mathrm{D}+\mathrm{E})$ was almost independent of $M_{\mathrm{n}}$. This indicates that the methoxy group is converted to the silanol group by hydrolysis and then into siloxane bond by oligomerization. Throughout this

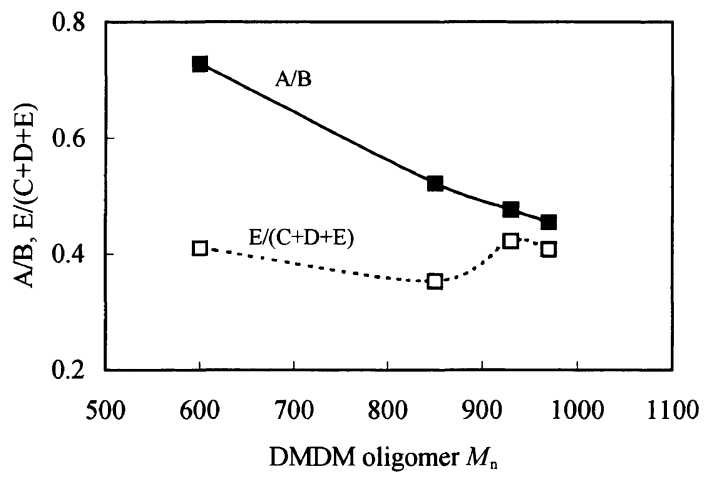

Figure 4. Fraction of unreacted methoxy group $\mathrm{A} / \mathrm{B}$ and fraction of linear siloxane $\mathrm{E} /(\mathrm{C}+\mathrm{D}+\mathrm{E})$. Concentration, 5 vol\%; $\mathrm{HCl}, 4.0$ $\mathrm{mol} \%$ of methoxy group; annealed at $70^{\circ} \mathrm{C}$ for $5 \mathrm{~min}$.

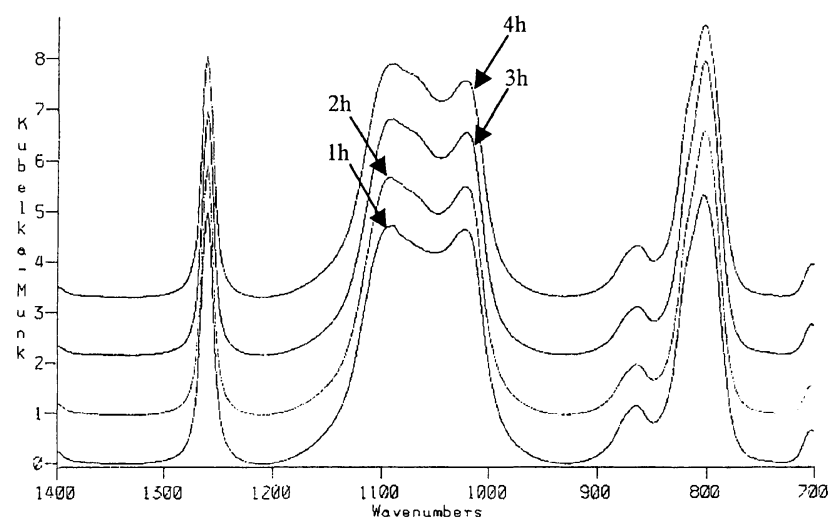

Figure 5. Effects of reaction time on IR spectra of DMDM oligomer after annealing. Concentration, 5 vol\%; annealed at $70^{\circ} \mathrm{C}$ for $5 \mathrm{~min}$.

reaction, however, the fraction of ring type siloxane is kept almost constant.

Bifunctional alkoxy compounds having four or more repeating units are likely to turn into 4-membered ring and the polymerization of these compounds proceeds by repeated ring opening and closure. Our results suggest that such ring opening and closure really occur also in the oligomerization of DMDM with 5 to 8 repeating units and thus the fraction of the linear siloxane component is kept almost constant. Figure 5 shows the IR spectra where such DMDM oligomer solution is heated at $70^{\circ} \mathrm{C}$ for $5 \mathrm{~min}$. When the time of the pre-reaction was longer, slight increase in the absorption at 1070 to $1090 \mathrm{~cm}^{-1}$ was observed indicating that the fraction of the ring siloxane component slightly increased.

Effects of $\mathrm{HCl}$ Concentration and Annealing Temperature upon Siloxane Structure

We examined the effects of the concentration of catalyst $\mathrm{HCl}$ on the formation of the oligomer and siloxane structure. Figure 6 shows the relationship between the fraction of unreacted methoxy group (A/B) and concentration of $\mathrm{HCl}$ after annealing. All reactions were carried out at 5 vol\% DMDM for $1 \mathrm{~h}$. The molar ratio of $\mathrm{HCl}$ against methoxy group of DMDM was changed from 0 to 0.4 . There were almost no remaining methoxy groups irrespective of $\mathrm{HCl}$ concentration except for the reaction carried out without $\mathrm{HCl}$ (Figure 6). As shown in Figure 


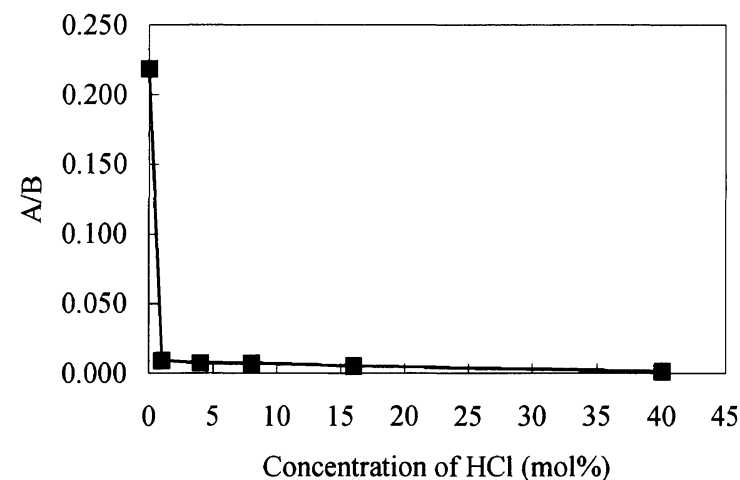

Figure 6. Plots of unreacted methoxy group A/B against $\mathrm{HCl}$ concentration. Concentration, 5 vol $\%$; annealed at $70^{\circ} \mathrm{C}$ for $5 \mathrm{~min}$.

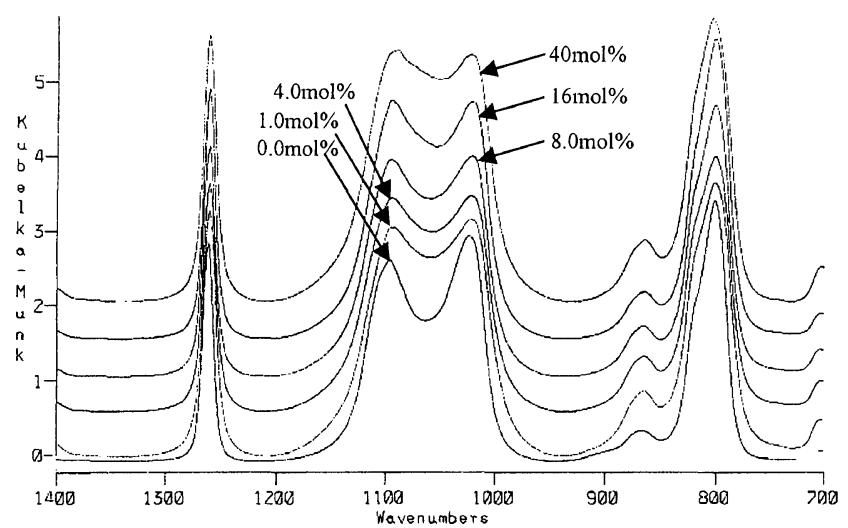

Figure 7. Effects of $\mathrm{HCl}$ concentration on IR spectra of DMDM oligomer after annealing. Concentration, 5 vol\%; annealed at $70^{\circ} \mathrm{C}$ for $5 \mathrm{~min}$.

4, A/B of DMDM oligomer solution was about $1 \mathrm{~h}$ after pre-reaction. Therefore we conclude that almost all methoxy groups react in the annealing process. Figure 7 shows IR spectra of DMDM oligomer after annealing. The relative intensity of the absorption in the vicinity of 1070 to $1090 \mathrm{~cm}^{-1}$ corresponding to ring siloxane component slightly increased with $\mathrm{HCl}$.

Next we examined the effects of the concentration of DMDM on the siloxane structure after annealing. The concentration of DMDM was changed from 0.1 to $20 \mathrm{vol} \%$ and the molar ratio of $\mathrm{HCl}$ against methoxy group was 0.4 . The reaction was carried out for $1 \mathrm{~h}$ and the resulting oligomer was annealed at $70^{\circ} \mathrm{C}$ for $5 \mathrm{~min}$. Figure 8 shows IR spectra of annealed oligomer for various initial DMDM concentrations. The relative intensity of the absorption in the vicinity of $1080 \mathrm{~cm}^{-1}$ decreased with increasing concentration of DMDM in the initial solution. That is, the ring siloxane is more easily formed at higher concentration of DMDM as in the case of longer reaction time or higher $\mathrm{HCl}$ concentration. These cases correspond to higher molecular weight DMDM oligomer formation in solution. Thus we conclude that the high molecular weight DMDM oligomer is more easily transformed into the ring siloxane component upon annealing.

Effects of annealing temperature on IR spectra are shown in Figure 9. The reaction was carried out with 5 vol\% of DMDM and $1.0 \mathrm{~mol} \% \mathrm{HCl}$ of methoxy group. An-

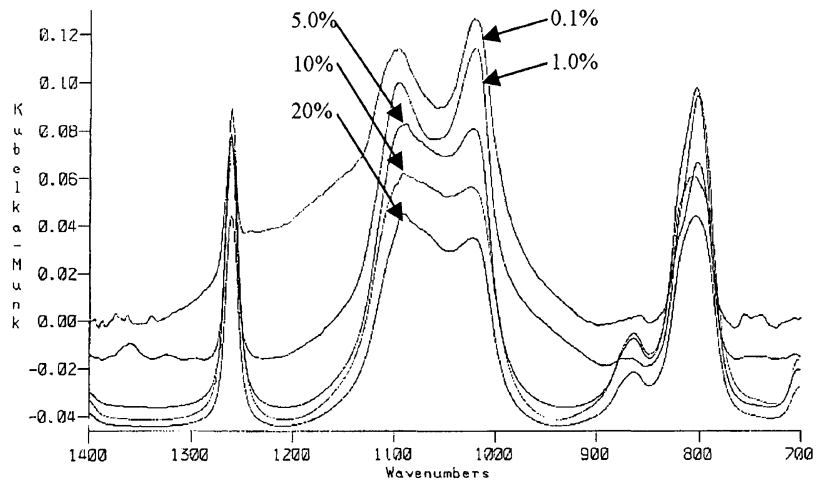

Figure 8. Effects of DMDM concentration on IR spectra of DMDM oligomer after annealing. Concentration, $0.1-20$ vol\%; annealed at $70^{\circ} \mathrm{C}$ for $5 \mathrm{~min}$.

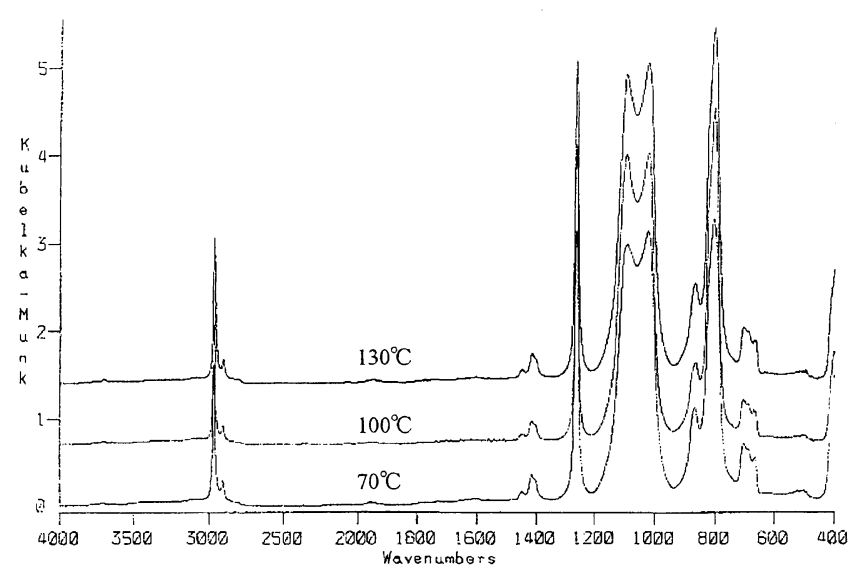

Figure 9. Effects of annealing temperature on IR spectra of DMDM oligomer. Concentration, 5 vol\%; annealed at 70, 100, and $130^{\circ} \mathrm{C}$ for $5 \mathrm{~min}$.

nealing time was 5 min at any temperature. We could not observe differences in the spectrum obtained at different temperatures, indicating that annealing temperature is not important in structure transformation during annealing process.

\section{Effects of Catalyst upon the Structure of Siloxane}

We studied the effects of the reaction catalyst on the structure of siloxane. In addition to $\mathrm{HCl}$, we used $\mathrm{DMF}$, as a basic catalyst, to enhance the polymerization of siloxane. ${ }^{14}$ In every case, the concentration of initial DMDM and catalyst concentration was 5 vol\% and 1.0 mol\% catalyst/( 1 mol methoxy group), respectively. Reaction time was $4 \mathrm{~h}$ at room temperature.

Figure 10 shows the IR spectra (CIRCLE) of DMDM oligomer solution before annealing. In every spectrum we observed strong absorption in the vicinity $1030 \mathrm{~cm}^{-1}$, while absorption in the vicinity of $1090 \mathrm{~cm}^{-1}$ was stronger for the spectrum without catalyst or with DMF catalyst compared with the $\mathrm{HCl}$ catalyst. A well-defined strong peak appeared in the vicinity of $1070 \mathrm{~cm}^{-1}$ only in the spectrum of the solution obtained in the presence of DMF catalyst. This indicates that linear and small membered ring siloxanes are predominant in solution obtained without catalyst and with $\mathrm{HCl}$, while considerable amounts of macro-cyclic ring siloxanes are formed 


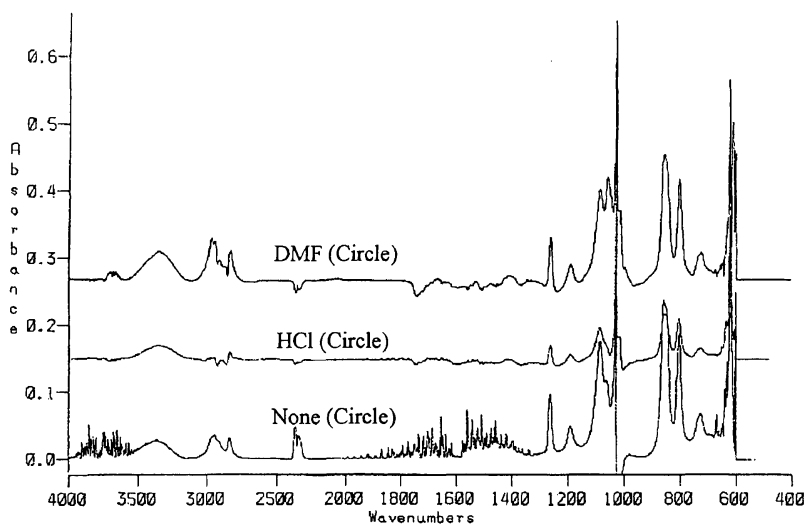

Figure 10. Effects of catalyst on IR spectra of DMDM oligomer. Concentration, 5 vol\%.

$$
\begin{aligned}
& \mathrm{MD}_{\mathrm{x}} \mathrm{M}+\mathrm{MD}_{\mathrm{y}} \mathrm{M} \rightleftarrows \mathrm{MD}_{\mathrm{x}-\mathrm{w}} \mathrm{M}+\mathrm{MD}_{\mathrm{y}+\mathrm{w}} \mathrm{M} \\
& \mathrm{MD}_{\mathrm{x}} \mathrm{M} \rightleftarrows \mathrm{MD}_{\mathrm{x}-\mathrm{w}} \mathrm{M}+\mathrm{D}_{\mathrm{w}}
\end{aligned}
$$

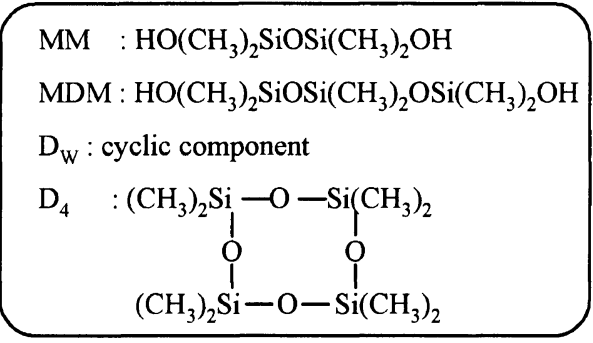

Figure 11. Equilibrium in siloxane polymerization.

in the solution obtained with DMF catalyst.

Siloxane polymerization and rearrangements are shown in Figure 11. ${ }^{15} \mathrm{M}$ and $\mathrm{D}$ denote terminal and internal siloxane units, respectively. Equation 1 in Figure 11 is a rearrangement reaction of two linear siloxanes to form other siloxanes with different lengths, while eq 2 denotes decomposition of a linear siloxane to form one linear and one cyclic siloxanes.

The mechanisms of polysiloxane formation from DMDM in acidic and basic solutions are shown in Figure $12 .^{16,17}$ Under acidic conditions, an oxonium ion is formed in the first place followed by reaction with water to form compounds with silanol groups. The condensation of silanol groups produces linear polysiloxanes by repeated nucleophilic attack of the silanols on the oxonium ion. The formation of oxonium ion is more likely on terminal siloxane unit (M) than an internal one (D), because of the higher reactivity of more basic $M$ with acids. Therefore rearrangement reactions such as eqs 1 and 2 in Figure 11 hardly occur under acidic conditions. Only cyclic species in acidic solutions may be formed by intramolecular condensation of terminal silanols.

Under basic conditions, silanols are formed by nucleophilic attack of the hydroxide ion on silicon atoms. Nucleophilic attack by hydroxide ion is more easily on internal silicon atoms on a siloxane chain followed by hydrolysis which leads to rearrangement reactions such as eqs 1 and 2 in Figure 11. The fraction of ring siloxanes becomes higher than acidic conditions due to the

\section{- Acidic solution}

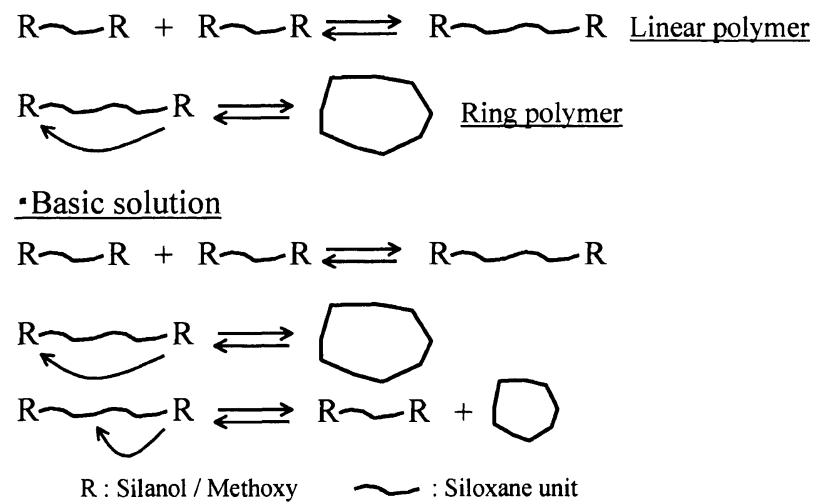

Figure 12. Mechanism for formation of linear and ring siloxanes in acidic and basic solutions.

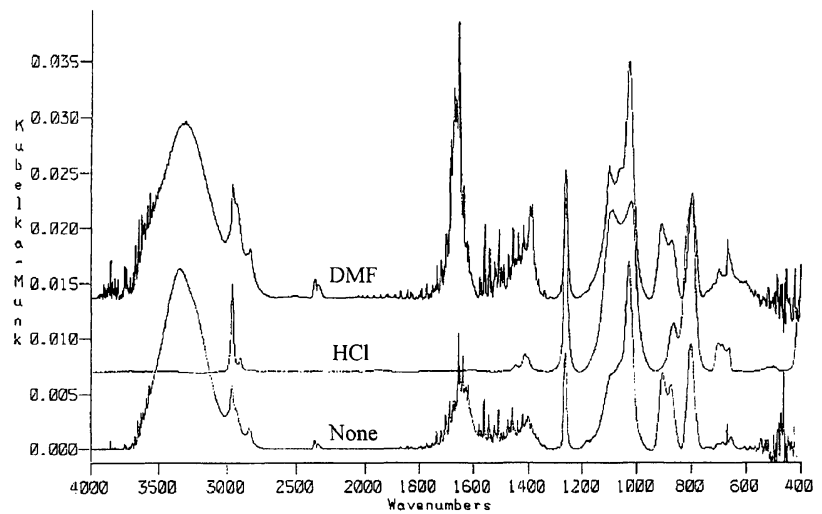

Figure 13. Effects of catalyst on IR spectra of DMDM oligomer after annealing. Concentration, 5 vol\%; annealed at $70^{\circ} \mathrm{C}$ for $5 \mathrm{~min}$.

equilibration of eq 2 . Such equilibration is likely responsible for increase ring component in annealing of polysiloxane solution obtained by acid catalysis.

We examined the effects of the catalyst on the structure of siloxane after annealing (Figure 13). Annealing was carried out at $70^{\circ} \mathrm{C}$ for $5 \mathrm{~min}$. On comparing Figures 10 and 13 , absorption in the vicinity of 1070 to 1090 $\mathrm{cm}^{-1}$ seriously increases by annealing for the siloxane obtained with $\mathrm{HCl}$, while that for the siloxane obtained without catalyst or with DMF is not appreciably changed by annealing. The ratio of remaining methoxy group (A/B) was compared before and after annealing in Figure 14 (before anneal; CIRCLE, after anneal; diffuse reflectance method). Disappearance of the methoxy group by annealing was remarkable only for the siloxane obtained with $\mathrm{HCl}$. Figure 15 shows the ratio of the linear siloxane component $(\mathrm{E} /(\mathrm{C}+\mathrm{D}+\mathrm{E}))$ before and after annealing (before anneal; CIRCLE, after anneal; diffuse reflectance method). Although the ratio was highest for $\mathrm{HCl}$ before annealing, it became lowest after annealing. The ratio of linear siloxanes for $\mathrm{HCl}$ system was about 60 to $70 \%$ those for other systems. It should be noted that the ratio of ring components is very much dependent on the catalyst, while the ratio reaches similar values after annealing. This qualitatively coincides with the equilibration mechanism shown in Figures 11 and 12 . 


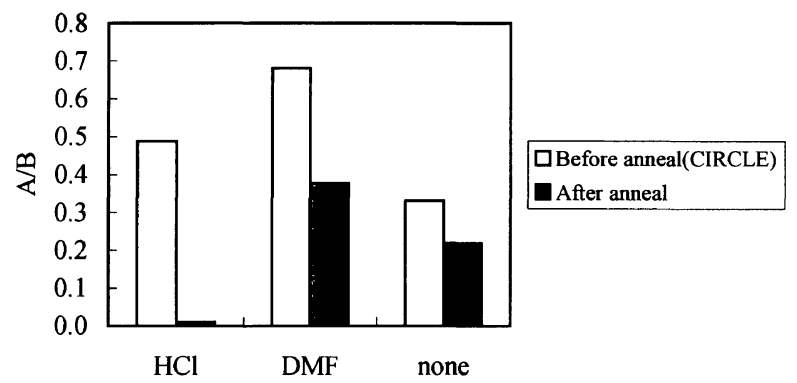

Figure 14. Effects of catalyst on the fraction of unreacted methoxy group A/B. Concentration, 5 vol\%; annealed at $70^{\circ} \mathrm{C}$ for 5 $\min$.

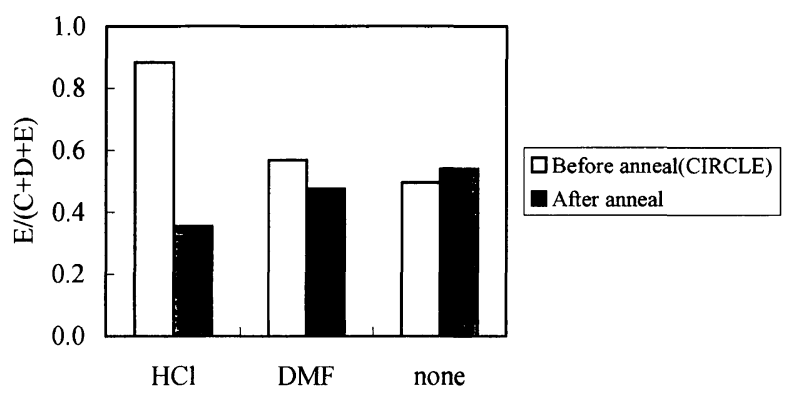

Figure 15. Effects of catalyst on the fraction of linear siloxane component $\mathrm{E} /(\mathrm{C}+\mathrm{D}+\mathrm{E})$. Concentration, 5 vol\%; annealed at $70^{\circ} \mathrm{C}$ for 5 min.

These results suggest that the linear oligomer of $\mathrm{DMDM}$ is formed in the presence of $\mathrm{HCl}$ and is converted into ring siloxane by annealing. The ring siloxane is likely to be generated in the system where the ratio of linear siloxane component in solution is high, as when $M_{\mathrm{n}}$ of DMDM oligomer is high, as discussed above.

\section{CONCLUSION}

We investigated the chemical structures of oligomeric siloxanes obtained from DMDM by FT-IR analysis. Structural transformation under heat treatment was examined. The results are as follows:

1) Using FT-IR CIRCLE, we resolved linear and ring siloxane components of oligomeric DMDM solution. Quantitative separation of these components was possible.

2) Almost all siloxane components in DMDM oligomer solution were linear components. About $50 \%$ of them were converted into ring components after heat treatment.

3) Unreacted methoxy groups in DMDM oligomer decreased with increasing molecular weight, while the fraction of the linear component in the oligomer was almost unchanged.

4) The fraction of ring component of annealed oligomer slightly increased with pre-reaction time, concentration, and by the addition of $\mathrm{HCl}$.

5) The fraction of linear siloxane component of the oligomer obtained with $\mathrm{HCl}$ catalyst was higher than without catalyst or with DMF catalyst. The oligomer obtained with $\mathrm{HCl}$ was easily converted into the ring siloxane annealing. The fractions of linear and ring components of the oligomer obtained without catalyst and with DMF were almost unchanged by annealing.

The fraction of linear siloxane component in the oligomer obtained from dimethoxy dimethylsilane was high, but the fraction decreased with annealing by transformation into ring siloxane component. To establish an interphase with low elastic modulus, it is necessary to form a linear siloxane component, which is difficult to undergo transformation into ring siloxane in annealing. Thus it is very important to optimize the number of substituent groups of starting silane, catalyst, and concentrations of reactants.

\section{REFERENCES}

1. H. Yoshida and M. Ikeno, Hyomen (in Japanese), 21, 159 (1983).

2. H. Ishida, Sen'i To Kogyo (in Japanese), 44, 56 (1988)

3. C.-H. Ching and J. L. Koening, J. Polym. Sci., Polym. Phys. Ed., 20, 2135 (1982).

4. N. Nishiyama, R. Shiuck, and H. Ishida, J. Colloid Interface Sci., 143, 146 (1991).

5. M. Yamatani, Nippon Setchaku Kyoukaishi (in Japanese), 27, 246 (1991).

6. S. Takahashi, Polyfile (in Japanese), December, 42 (1993).

7. N. Takano, T. Fukuda, K. Ono, Kobunshi Ronbunshu (in Japanese), 57, 743 (2000).

8. K. Nishikida, "FT-IR as Viewed on Chart" (in Japanese), Kodansha, Tokyo, 2000

9. N. Ikuta, Collection of abstracts on 3rd Symposium on Composite Material Interface, 34, 102 (1994).

10. S. C. Culler, 40th Annual Conference, Reinforced Plastics/ Composites Institute. The Society of the Plastic Industry, Inc., 1985, Jan. 28, Feb. 1.

11. A. Gunji and Y. Abe, Ceramics, 31, 469 (1996).

12. M. Tanaka and N. Teramae, "Infrared Spectroscopy" (in Japanese), Kyoritsu Shuppan, Tokyo, 1998, 134-137.

13. H. Horiguchi, Ed., "Pictorial Conspectus of Infrared Absorption" (in Japanese), Sankyo Shuppan, Tokyo, 1973, 329-331.

14. "Handbook on Silicone Material", Toray Dow Corning Silicone, Co., Ltd., 1993.

15. W. Patnode and D. F. Wilocock, J. Am. Chem. Soc., 68, 358 (1946)

16. T. C. Kendrick, J. Chem. Soc., 2027 (1965).

17. J. F. Brown and G. M. J. Slusarczuk, J. Am. Chem. Soc., 87 931 (1965). 